\title{
PREDICTORS OF HYPERTENSION
}

\author{
Stevo Julius * and M. Anthony Schork $\dagger$ \\ Department of Internal Medicine, School of Medicine * \\ Department of Biostatistics, School of Public Health $\dagger$ \\ University of Michigan \\ Ann Arbor, Michigan 48109
}

\section{The Problem}

A good understanding of predictors of hypertension should allow the selection of populations with a sufficiently high incidence of later hypertension to warrant preventive use of antihypertensive drugs. Much more work on predictors of hypertension is needed, however, before it will be possible to select such a group. This is illustrated by the best-known and strongest predictor of future hypertension-so-called borderline hypertension. We use the term "borderline hypertension" to apply to persons (1) whose blood pressure oscillates between normal $(139 / 89$ or less) and elevated $(>139 / 89)$ values and (2) to persons whose average casual blood pressure is in the range of 140-160/90-100. In borderline hypertension, the risk of future hypertension is higher than in the general population; however, the risk is not overwhelming and the majority of patients will not develop hypertension; thus, patients with borderline hypertension cannot be treated as a uniform population with excess morbidity, and it is important to identify the subgroup of future hypertensive patients. The papers upon which this statement are based ${ }^{1-10}$ have been discussed in a previous review. ${ }^{11}$ The validity of the statement can be illustrated in the light of results of efficacy of the antihypertensive treatment in mild hypertension utilizing the data from the Veterans Administration Cooperative Study. ${ }^{12}$

Consider the following projection based on the assumptions that: (1) the treatment is likely to be less effective in borderline hypertension than in mild hypertension described in the VA Study, and (2) in 5 years $10 \%$ of patients with borderline hypertension would progress to develop hypertension of the degree investigated in the VA Study (sustained diastolic 90-115). The first assumption need not be defended; the lower the initial blood pressure, the less is the effectiveness of the treatment. ${ }^{12,13}$ The $10 \%$ figure for a 5-year incidence of hypertension is based on available literature for middle-aged subjects with previous borderline hypertension (Table 3 in reference 11).

Using the VA article, page 167, and Figure 2 (page 168), and a 5-year follow-up, the following values were obtained:

1. If hypertensives with diastolic blood pressure between $90-114 \mathrm{~mm} \mathrm{Hg}$ are untreated, $55 \%$ will have a morbid event in five years.

2. The standard deviation for this untreated rate is $4.0 \%$.

Thus, using an approximate $95 \%$ confidence interval ( \pm 2 S.D.) to find a range of untreated values, we get:

lower limit for 5-year untreated rate: $55 \%-8 \%=47 \%$

upper limit for 5 -year untreated rate: $55 \%+8 \%=63 \%$. 
Now, using $47 \%, 55 \%$ and $63 \%$ as three untreated 5-year percentages of patients having a morbid event, we can consider several choices for "effective reduction" in that percentage due to treatment. Suppose we take for these: reduced by $2 / 3$ (VA result), $1 / 2$, and $1 / 4$, a $67 \%, 50 \%$ and $25 \%$ reduction, respectively.

With these values we can illustrate various percentages of persons at risk (to develop diastolic blood pressure $90-114 \mathrm{~mm} \mathbf{~ H g}$ during the proposed period of treatment) who will be "saved" from a morbid event in the next five years, if the entire population with borderline hypertension is treated with antihypertensive therapy.

TABLE 1

Percentage of Total Population of Borderline Hypertensives Who Would Be Saved from a Morbid Event by Various Postulated Treatment Efficacies *

\begin{tabular}{cccc}
\hline \multirow{2}{*}{$\begin{array}{c}\text { Untreated Morbidity } \\
\text { For Hypertensives }\end{array}$} & $3 / 3(67 \%)$ & $1 / 2(50 \%)$ & $1 / 4(25 \%)$ \\
\cline { 2 - 4 } $47 \%$ & 3.13 & 2.35 & 1.17 \\
& 2.50 & 1.88 & 0.94 \\
$55 \%$ & 3.67 & 2.75 & 2.37 \\
& 2.94 & 2.20 & 1.10 \\
$63 \%$ & 4.20 & 3.15 & 1.57 \\
& 3.36 & 2.52 & 1.26 \\
\hline
\end{tabular}

* The percentages in italics assume $80 \%$ instead of $100 \%$ of the subjects adhere to the treatment.

The assumptions in TABLE 1 can be changed. To find percentage "saved" for populations with different percentages at risk, multiply the value in table by the appropriate multiple of $10 \%$ : e.g., if $30 \%$ of population have diastolic blood pressure $90-114 \mathrm{~mm} \mathrm{Hg}$ and untreated percentage is $55 \%, 2 / 3$ reduction, $3.67 \times 3=11.01 \%$ are "saved".

To find percentage "saved" for population with adherence other than $100 \%$, multiply the value in table by percent adhering; e.g., if untreated percentage is $55 \%$ and $2 / 3$ reduction and $80 \%$ adhere, $3.67 \times 0.80=2.94 \%$.

If the proportion at risk (to develop diastolic $90-114 \mathrm{~mm} \mathrm{Hg}$ ) is $10 \%$, the values for the percentage "saved" can be calculated (TABLE 1 ).

There are obvious limitations to the calculations presented in TABLE 1 . Treatment in younger persons may be more beneficial than in middle-aged subjects investigated in the VA Study. We assumed that the treatment at lower blood pressure levels will be less effective than in the VA Study, but some unaccounted usefulness at these lower levels may exist. However, on the whole, the projection in TABLE 1 is weighted in favor of the treatment. An unusually high rate of patient compliance has been anticipated. In practice one could not expect the compliance to approach levels demonstrated in the VA Study. In that study potentially noncompliant patients have been eliminated at the outset of the trial. Furthermore, the $10 \%$ prevalence rate of "advanced" 
hypertension is calculated as if all patients developed diastolic readings $90-114$ at once at the beginning of treatment.

TABLE 1 illustrates the very real need to improve the prediction of future hypertension. Even though borderline hypertension is the strongest known predictor of hypertension, it cannot be used as the sole criterion for patient selection for treatment. One hundred patients with borderline hypertension would have to receive medication for 5 years in order to show benefit at best in four and at worst in one subject. This obviously is not a practical proposition. Tools for better prediction of future hypertension need to be developed. A second illustration will be presented following a discussion of the current status of knowlege about predictors of hypertension.

\section{Prediction of Future Hypertension}

Basically there are two methods to search for prospective patients with hypertension, (1) provocative tests and (2) descriptive characteristics.

\section{Provocative Tests}

Many provocative tests are based on the assumption that an exaggerated pressor response, if elicited, is representative of a trend toward future hypertension. The basic assumption that repeated pressor episodes lead to hypertension has never been properly tested. In fact, animal experimentation with removing arterial baroreceptors in dogs shows that numerous pressor episodes do not lead to established hypertension. ${ }^{14}$ Repeated pressor episodes from mental stress in squirrel monkeys, ${ }^{15}$ from hypothalamic stimulation of rats, ${ }^{16}$ and from "social" stress in mice ${ }^{17}$ are said to cause "established" hypertension. However, severity of "established" hypertension under these experimental conditions does not resemble true human established hypertension. A malignant hypertension by means of repeated pressor episodes has yet to be created.

\section{Cold Pressor Test}

Hines originally proposed that hyperresponsiveness to cold may be a useful tool for predicting future hypertension. ${ }^{18} \mathrm{He}$ viewed "labile" hypertension as a strong precursor of hypertension and found cold pressor hyperresponsiveness to be typical for labile hypertension. These expectations have not been confirmed in subsequent studies. Hyperresponsiveness to cold is not a characteristic trait in borderline hypertension. ${ }^{19,} 20$ In the normotensive range there is no correlation between baseline blood pressure and the cold pressor test. ${ }^{21,} 22$ Finally, the cold pressor test has been evaluated in a prospective study and failed to predict future hypertension. ${ }^{22}$

\section{Response to Exercise}

C. B. Thomas originally proposed that blood pressure response to exercise may be exaggerated in subjects who are prone to later hypertension. ${ }^{23}$ How- 
ever, to our knowledge, in later studies from her laboratory the predictive value of exercise responses has not been evaluated. Newer studies with intraarterial blood pressure measurement failed to confirm an excessive blood pressure response in young subjects with borderline hypertension. ${ }^{24-27}$

Tilt

It has been shown that tilting causes hypertensive responses in a proportion of patients with mild hypertension. ${ }^{28,}{ }^{29}$ The predictive value of this hyperreactivity has not been investigated.

\section{Psychological Stress}

Mental arithmetic elicits a higher pressor response in patients with borderline hypertension. This higher response is coupled with more catecholamine excretion than in normal subjects. ${ }^{30}$ Although it is conceptualized that stress may lead to hypertension, ${ }^{31}$ the predictive value of an excessive blood pressure response to mental stress has not been established.

\section{Descriptive Characteristics}

Numerous descriptive variables have been cross-sectionally associated with hypertension. One phenomenon may be associated to another as a cause or consequence, or in a parallel (related or unrelated) fashion. It therefore cannot be expected that all cross-sectional correlates of hypertension will predict the devolopment of future hypertension, but some of them may have such a predictive potential. Only a few descriptive characteristics have been actually investigated for their potential and strength as prospective predictors of the development of hypertension.

\section{Blood Pressure Levels}

It would be beyond the scope of this paper to review the substantial evidence that initial blood pressure levels are the strongest single known predictor of future hypertension. Longitudinal following of cohorts of individuals shows that those who were normotensive, but whose blood pressure was in the upper range, exhibited a steeper blood pressure increase with age.1, 32 Analyzed in terms of development of "hypertension," the results are identical; in groups whose initial blood pressure was in the upper quintile, there will be more individuals with hypertensive blood pressure levels with passage of time. ${ }^{9,}{ }^{33}$

The strength of the blood pressure as predictor by far exceeds the power of all other factors that are known to predict future hypertension. ${ }^{34}$ Stamler et $a l^{34}$ have shown that the several factors considered in their analyses (age, relative weight, heart rate, plasma glucose, serum cholesterol, serum uric acid, and cigarettes) are not strongly correlated with followup blood pressure when baseline blood pressures and the remaining factors are partialled out. Similar results obtain in multiple logistic analyses wherein baseline blood pressures 
are the only consistent (across cutoff points for elevated followup blood pressure) predictors of elevated blood pressure.

\section{Heart Rate}

Increased heart rate is associated with mild and borderline hypertension. ${ }^{11}$ It is now also clear that elevated heart rate is an independent predictor of future hypertension. ${ }^{7}$, 33-35 The predictive power, however, appears to be weak. ${ }^{34}$

\section{Overweight}

Overweight is associated with mild and borderline hypertension. Relative weight is a predictor of future hypertension but, similarly to the heart rate, the predictive power is not strong. ${ }^{9,34}$

\section{Family History}

Family history of hypertension is significantly more frequent in patients with borderline hypertension. ${ }^{38}$ Later hypertension appears to occur more frequently in persons with positive family history. ${ }^{37}$ We could not assess the relative predictive strength of these parameters.

\section{Psychological Factors}

Some distinctive behavioral and personality patterns appear to be associated with borderline hypertension. ${ }^{38-40}$ The hope that these factors may predict future hypertension has not materialized.

Race

One can construe from the results of the National Health Survey 1960-62 41 that marginal blood pressure elevation in a black person carries a higher risk for future hypertension than in whites. Thus in the overall population aged 18-79 the prevalence of borderline hypertension in whites and blacks (both sexes) is very similar, but definite hypertension is found twice as frequently in blacks as in whites. Assuming that in the majority of cases hypertension evolves through a phase of borderline blood pressure elevation, it is reasonable to postulate that a black person with borderline hypertension has double the chance of later developing established hypertension.

\section{Prediction Based on Multiple Factors}

Until now predictive variables have been considered one at a time. It is possible that simultaneous use of a number of variables may be more predictive than each variable separately. This proposition has been extensively evaluated 
in an important recent paper describing the experience of four Chicago epidemiologic studies. ${ }^{3+}$ Using the multiple logistic function (including variables: baseline blood pressures, age, heart rate, serum cholesterol, one-hour plasma glucose, relative weight, and hematocrit) to discern that quintile of the population with highest risk of developing hypertension within 5 years, Stamler et al. . $^{34}$ found at most $55 \%$ of all expected hypertensives will be in that quintile. Further, assuming that $10 \%$ of the total population from which this quintile has been culled will become hypertensive in 5 years, then approximately $27.5 \%$ of this quintile would become hypertensive. (Fifty-five percent of $10 \%$ is $5.5 \%$. This $5.5 \%$ is to be found in the highest quintile of the population. Thus $27.5 \%$ $[=5.5 \% \times 5]$ of this quintile must be hypertensive, to represent $5.5 \%$ of the total population.)

\begin{tabular}{l}
\hline $\begin{array}{l}\text { Prevalence of Hypertension } \\
\text { in the Highest Risk Quintile }\end{array}$ \\
$\begin{array}{l}\text { Distribution } \\
\text { Mntreated }\end{array}$ \\
$\begin{array}{l}\text { Treatment } \\
\text { Efficacy }\end{array}$
\end{tabular}

FIGURE 1. Projection of treatment efficacy using multifactorial hypertension risk screening (treat all subjects in the upper quintile of risk).

We now assess the hypothetical efficacy of antihypertensive treatment in this quintile with highest predicted risk, using these results based on Stamler et $\mathrm{al}$. and those of the Veterans Administration studies. ${ }^{12,13}$ The VA results indicate that $55 \%$ of those with diastolic blood pressure $90-115$ will have a morbid event in 5 years, while about $80 \%$ of those with diastolic blood pressure above 115 would have such an event in 5 years. It is estimated that $90 \%$ of all hypertensives have diastolic blood pressure $90-115$ and $10 \%$ are above 115.11 The VA results indicate that treatment can save about $67 \%$ of those with diastolic 90-115 and $90 \%$ of those with diastolic $115+$ from a morbid event.

Using calculations similar to those illustrated in TABLE 1 (see Figure 1), 
about $11.2 \%$ of this highest risk quintile would be saved from a morbid event due to hypertension in 5 years $(9.2 \%$ of those with diastolic blood pressure 90-115 and $2.0 \%$ of those with diastolic blood pressure above 115 ).

Therefore, even using the most optimistic figures available, only about $11.2 \%$ of the group predicted to be at highest risk of hypertension would be saved from a morbid event. The conclusion is that populations which will contain the vast majority of future hypertensives must be ascertained with greater certitude than presently predictable, if widescale antihypertensive therapy is to have appreciable efficacy in large populations.

\section{Pathophysiology of Borderline Hypertension}

As arterial hypertension develops, many secondary cardiovascular changes occur. Restructuring of resistance vessels, ${ }^{42,}{ }^{43}$ altered cardiac performance, ${ }^{44}$ and resetting of arterial baroreceptors ${ }^{45}$ are some of the examples. Consequently, many investigators have focused on "prehypertension" in the hope of finding a model of very mild hypertension free of secondary pressure-related changes. The limitations of this approach are obvious from the previous sections. Marginal blood pressure elevation is the strongest predictor of future hypertension, but the incidence of future hypertension is low. Consequently it is not known which observations in borderline hypertension are pertinent and which are not related to the later development of hypertension. The problem becomes particularly clear when one considers the wide range of abnormalities observed in borderline hypertension, shown in TABLE 2. Two points emerge from TABLE 2: (1) Borderline hypertension is not just a "little blood pressure elevation"; a number of physiologic aberrations are observed. Many of these abnormalities were found in patients who had a history of occasional blood pressure elevation, but during the laboratory testing were normotensive. Behind the facade of borderline hypertension, unrelated to the blood pressure elevation, a complex of physiologic abnormalities can be detected. (2) From a physiologist's viewpoint, borderline hypertension is not a homogeneous disease. Some of the abnormalities are polar (high and low stroke volume, high and low plasma renin activity), some are present only in a minority of patients (elevated cardiac output, redistribution of the blood in the capacity space, decreased plasma volume) whereas those present in all patients (abnormal peripheral resistance) may be coupled with the presence or absence of other abnormalities.

The complexity of changes in borderline hypertension militates against the simplified statistical view of hypertension as the upper end of the normal blood pressure distribution. Failure to demonstrate two separate peaks of blood pressure distribution does not preclude the possibility that the development of blood pressure in various individuals occurred through different mechanisms. The variety of findings in borderline hypertension offers the exciting possibility that occurrence of hypertension may be favored or delayed by some of these abnormalities, and that some other observations may be entirely unrelated to the development of later hypertension. Only epidemiologic studies can provide the answer.

Clustering of some of the pathophysiologic abnormalities into certain patterns provides further support for the assumption that borderline hypertension is not a homogeneous condition and groups with such patterns may have different natural histories. Description of patterns very much depends on the investi- 
gator's interest. For example, the level of plasma volume may be chosen as the primary descriptor and other correlates could then be analyzed. In the laboratory in Ann Arbor, the role of the autonomic nervous system is under special scrutiny. Our research findings are presented only as an illustration of pathophysiologic patterns that could conceivably be used to determine future research strategies.

TABLE 2

Physiologic Abnormalities in Borderline Hypertension *

1. Biochemical indices of sympathetic activity elevated to

2. Cardiac index elevated ${ }^{2}$

3. Tachycardia ${ }^{47}$

4. Stroke volume elevated ${ }^{48}$ decreased *

5. Peripheral resistance abnormal elevated ${ }^{\text {so }}$ inappropriately adjusted to flow ${ }^{51}$

6. Peripheral to central distribution of the blood in the capacitance vessels ${ }^{52}$

7. Plasma volume decreased ${ }^{53}$

8. Plasma renin activity abnormal

high ${ }^{47}$

low ${ }^{34}$

9. Vascular reactivity-increased ${ }^{\mathrm{s}}$

10. Increased blood pressure responsiveness

to tilt ${ }^{\circ}$

to mental stress ${ }^{30}$

11. Increased beta-adrenergic responsiveness

of the heart ${ }^{50}$

of renin release ${ }^{57}$

12. Abnormal forearm blood flow response to sodium loading ${ }^{\text {ss }}$

* Typical references for various observations are given; detailed reference can be found in a recent review. ${ }^{\text {so }}$

\section{"Neurogenic" Borderline Hypertension}

In these patients the cardiac output is elevated through a combination of a faster heart rate and a larger stroke volume. ${ }^{48}$ This elevation is neurogenic; after cardiac autonomic blockade with propranolol and atropine, the stroke volume and heart rate return into the normal range. ${ }^{60}$ Peripheral resistance in these cases is elevated through an increased alpha-adrenergic tone. ${ }^{54}$ After alpha-adrenergic blockade with phentolamine, the vascular resistance normalizes.

In this "neurogenic" borderline hypertension the cardiac sympathetic drive is increased, whereas the vagal inhibition of the heart is decreased. ${ }^{80}$ Such a reciprocal relationship of the sympathetic and parasympathetic efferent tone is typical for the functional organization of the integrative areas in the medulla 
oblongata. Thus the abnormality is not likely to reside in the peripheral neurons; an abnormal but integrated pattern of changes is present. ${ }^{59}$

It is now becoming evident that elevations of the plasma renin activity in borderline hypertension is also a part of the "neurogenic" pattern. Bimodal elevation of plasma renin activity described by Frohlich et al. ${ }^{47}$ was an early indication that high plasma renin in mild and severe hypertension may have different pathophysiologic significance. Esler et al. ${ }^{54}$ have shown that patients with high-renin borderline hypertension exhibit an increased alpha-adrenergic tone, and that the renin elevation per se is not responsible for the blood pressure elevation in such patients.

In this light, our recent study in patients with mild established hypertension who had a high plasma renin is of particular interest. ${ }^{61}$ In the absence of longitudinal studies, assumptions can be made from cross-sectional studies of various degrees of severity of hypertension. It is reasonable to assume that mild established hypertension (systolic always 150-160, diastolic 95-105) evolves from previous borderline hypertension (blood pressure above and below 140/90). Pathophysiologic similarities, if found in both "stages," may delineate those abnormalities in borderline hypertension that are likely related to the development of hypertension. Patients with high-renin established hypertension show essentially the same changes as the "neurogenic" subset of borderline hypertension. The cardiac output tends to be elevated and there is evidence of increased beta- and alpha-adrenergic drive. Furthermore, plasma catecholamine levels in such patients are elevated.

Further support for the possible pathogenic significance of the "neurogenic" borderline hypertension comes from epidemiologic studies. Tachycardia, which is the most consistent feature of the "neurogenic" borderline hypertension, has been shown in a number of studies to be an independent predictor of future hypertension. $.^{7}, 33-35$

\section{"Non-neurogenic" Borderline Hypertension}

The opposite end of the spectrum, the "non-neurogenic" borderline hypertension, also may have an elevated cardiac output. However, in these patients there is an isolated elevation of the stroke volume, whereas the heart rate is normal. ${ }^{62}$ Such patients have a redistribution of the blood in the capacity space; total blood volume is normal, but a larger proportion is maintained in the cardiopulmonary space. ${ }^{62}$ The elevated stroke volume appears to reflect effects of this volume distribution on cardiac performance. Cardiac output in these patients does not return to normal after cardiac autonomic blockade, and their peripheral resistance remains elevated after additional alpha-adrenergic blockade with phentolamine. Plasma renin activity in such patients is decreased.

Similarly, as in high-renin borderline hypertension, this pattern shows some pathogenic similarity with low-renin established hypertension. ${ }^{63}$ Catecholamine levels, response to tyramine, response to autonomic blockade in patients with low-renin established hypertension are indicative of a low sympathetic tone. However, established low-renin hypertension does not show such a homogeniety of hemodynamic patterns as high-renin established hypertension. Only a subgroup of low-renin established hypertension has similar hemodynamic features as low-renin borderline hypertension. 


\section{OPPORTUNITIES fOR FUtURE RESEARCh}

The pathophysiology of precursors of hypertension has already been investigated in selected population studies by Eich, ${ }^{64}$ Lund-Johansen, ${ }^{24}$ Finkielman et al., ${ }^{65}$ Bello et al., ${ }^{66}$ and Julius and Conway ${ }^{25}$ who included only male subjects. Sannerstedt, ${ }^{26}$ Frohlich et al., ${ }^{47}$ and Widimsky et al. ${ }^{67}$ included a small proportion of females in their studies. Populations in these studies were largely determined by local referral and hospitalization patterns. Lund-Johansen's study 24 was drawn from a large population, but the selection for laboratory studies was not random. Only one study ${ }^{68}$ analyzed hemodynamic patterns in a longitudinal fashion, but the population was too small to provide meaningful conclusions.

Descriptive epidemiologic studies of precursors of hypertension are characterized by an ever improving design and a higher level of sophistication of data analysis. Nevertheless it remains a fact that in the last two decades they have dealt with essentially the same variables. Whereas twin and family studies may improve our knowledge in the future, it is evident that hypertension is not a single entity and certainly not a single-gene disease. In whom, why and how does the tendency to hypertension express itself will still remain an open question.

Real progress can only be made if the expertise in both fields is combined. There should be a move from descriptive epidemiology and laboratory studies on selected populations, to investigations of pathophysiology in an epidemiologic setting.

A number of non-invasive tests of hemodynamics are now available. Cardiac output can be estimated by echocardiography and by the carbon dioxide rebreathing method. Systolic time intervals provide a new dimension in assessing myocardial contractility. Measurement of plasma volume by Evans blue remains a safe and simple procedure. Responsiveness to pharmacologic blockade can be used to assess the neurogenic drive. Measurements of plasma catecholamines are now sensitive and precise. Plasma renin activity can be measured, but in the future we may rely also on blood pressure responses to angiotensin antagonists. Determination of circulating angiotensin II levels may soon become dependable. Better assays of prostaglandins will be available. Urinary kallikrein has already been measured in an epidemiologic study. ${ }^{69}$

A number of these and other methods can be used in prospective studies to enhance the understanding of hypertension. In cross-sectional investigation, analysis of family sets and twin studies of various physiologic variables are particularly promising approaches.

Although many more examples can be found, we will illustrate four major categories where combining the epidemiologic and pathophysiologic approaches may yield important results. No attempt is made to define "epidemiologic." Obviously in some studies noninvasive methods may be applied in large populations whereas in other instances precise physiologic measurements in representative samples of populations chosen for various levels of risk may be indicated.

\section{Evaluation of Pathophysiologic Concepts}

The hyperkinetic state offers a good illustration. ${ }^{60}$ It has been postulated that hypertension is initiated by a primary increase of the cardiac output which triggers a later "autoregulatory" increase of the peripheral resistance. ${ }^{70}$ The 
following questions should be asked: Is there evidence of a high cardiac output state in offspring of hypertensive parents before they exhibit hypertension? In prospective studies, do subjects with the hyperkinetic state tend to develop more hypertension than control subjects? For the same levels of marginal blood pressure elevation, does the hypertension develop more frequently and/or over a shorter period of time in the "hyperkinetic" or "high resistance" type of borderline hypertension? Are all hyperkinetic states the same, or does there exist a "neurogenic" and "volume" subset of subjects with elevated cardiac output-what is their prognosis?

Other pathophysiologic concepts also deserve attention. Is there good evidence for vascular hyperreactivity in precursors of hypertension? Can the precursors of hypertension be differentiated into "volume" and "vasoconstrictor" states and which one predicts more future hypertension? What is the role of the autonomic nervous system in the development of essential hypertension?

\section{Mechanisms of Risk Factors for Hypertension}

Overweight and hypertension lend themselves as ideal examples. The association between overweight and hypertension is well-documented.9, 34 What is its mechanism? Does increase of weight lead to blood pressure increases in everybody or only in selected cases? We suspect the latter to be the case. If so, what are the characteristics of such subjects? Do they show excessive plasma volume expansion for a given increase of weight; do their cardiac outputs and stroke volumes reflect volume effects on cardiac performance? Or, is increased appetite-weight gain an expression of increased "nervousness"; what are the catecholamine levels, psychometric characteristics, and indices of cardiac sympathetic activity in such subjects?

\section{Evaluation of Physiologic Variables as Possible Precursors of Hypertension}

A number of known correlates of borderline hypertension have not been investigated as prospective predictors of hypertension. Of specific interest here is the plasma volume, levels of catecholamines, renin levels and renin dependency of the blood pressure, differentiation between vagal and sympathetic tachycardia, state of peripheral vascular resistance, alpha-adrenergic dependency of the blood pressure and volume distribution in the capacity space.

\section{Possible New Provacative Tests}

A recent article by Mark and associates ${ }^{58}$ suggests to us that sodium loading may be a useful tool in evaluation of future hypertension. In short, they found that normotensive subjects on sodium loading decrease the forearm vascular resistance, whereas in patients with borderline hypertension on sodium load the forearm resistance increased. This opens a number of important and interesting possibilities. Can prediction of hypertension be improved by observing blood pressure, plasma volume, forearm flow, cardiac output, renin, and kallikrein responses to sodium loading?

It has already been pointed out earlier that blood pressure responses to 
tilting and mental stress deserve scrutiny as possible predictors of hypertension.

The specific examples in four categories are given only as an illustration of a variety of projects which could spring from cooperation between investigators with different backgrounds. Interaction between those familiar with mechanisms and those interested in epidemiology of hypertension could not fail to open new avenues in the search for precursors of hypertension.

\section{Summary}

The main justification of a search for predictors of future hypertension is in the hope of identifying a population in which it would be reasonable to initiate preventive antihypertensive treatment. We examined all the known risk factors for hypertension and found that, based on the present evidence in the literature, such a group cannot be selected.

A large body of information exists in the area of pathophysiology of "prehypertension," but this has never been used in an epidemiologic context. It is hoped that incorporation of new measurements testing various pathophysiologic alterations in future epidemiologic studies may improve prediction and provide insight into mechanisms of hypertension.

\section{REFERENCES}

1. Mathewson, F. A. 1966. Blood pressure in Canadian aviators: A fifteenth year report. Trans. Assoc. Life Insur. Med. Dir. 50: 219-226.

2. Chapman, J. M., E. R. Borun, F. J. Massey, et al. 1967. Blood pressure distributions in the Los Angeles Heart Study population, 1950-1963. In The Epidemiology of Hypertension: Proceedings of an International Symposium. J. Stamler, R. Stamler \& T. N. Pullman, Eds. : 98-100. Grune \& Stratton. New York.

3. Kooperstein, S. I., A. Schifrin \& T. J. Leahy. 1962. Level of initial blood pressure and subsequent development of essential hypertension: A 10 and 15 year follow-up study. Am. J. Cardiol. 10: 416-423.

4. Thomson, K. J. 1950. Some observations on the development and course of hypertensive vascular disease. Proc. Ann. Meet. Med. Sect. Am. Life Convention 38: 85-112.

5. Heyden, S., A. G. Bartel \& C. G. Hames, et al. 1969. Elevated blood pressure levels in adolescents, Evans County, Georgia: 7-year follow-up of 30 patients and 30 controls. JAMA 209: 1683-1689.

6. Levy, R. L., C. C. Hillman, W. D. Stroud, et al. 1944. Transient hypertension: Its significance in terms of later development of sustained hypertension and cardiovascular-renal disease. JAMA 126: 829-833.

7. Paffendarger, R. S., Jr., M. C. Thorne \& A. L. Wing. 1968. Chronic disease in former college students-VIII. Characteristics in youth predisposing to hypertension in later years. Am. J. Epidemiol. 88: 25-32.

8. Evans, W. 1957. Hypertonia or uneventful high blood pressure. Lancet 2: 53-59.

9. Stamler, J., H. A. Lindaerg, D. M. Berkson, et al. 1958. Epidemiological analysis of hypertension and hypertensive disease in the labor force of a Chicago utility company. Proc. Coun. High Blood Press. Res. 7: 23-52.

10. Julius, S., E. Harburg, N. F. McGinN, et al. 1964. Relation between casual blood pressure readings in youth and at age 40; A retrospective study. J. Chron. Dis. 17: $397-404$. 
11. Julius, S. \& M. A. SchoRK. 1971. Borderline hypertension-A critical review. J. Chron. Dis. 23: 723-754.

12. Veterans administration Cooperative Study Group on ANTHHypertensive AGENTs. 1970. Effects of treatment on morbidity in hypertension. JAMA 213: $1143-1152$.

13. Veterans Administration Cooperative Study Group on Antihypertensive AGENTS. 1967. Effects of treatment on morbidity in hypertension-I. JAMA 202: 1028-1034.

14. Cowley, A. W., JR., J. F. Liard \& A. C. GuYton. 1973. Role of the baroreceptor reflex in daily control of arterial blood pressure and other variables in dogs. Circ. Res. 32: 564-576.

15. Herd, J. A., R. T. Kelleher, W. H. Morse, et al. 1976. Behavioral modification of blood pressure in monkeys. In The Nervous System in Arterial Hypertension. S. Julius \& M. Esler, Eds. : 162-181. Charles C Thomas. Springfield, Ill.

16. Folkow, B. \& E. H. Rubinstein. 1966. Cardiovascular effects of acute and chronic stimulation of the hypothalamic defense area in the rat. Acta Physiol. Scand. 64: 84.

17. Henry, J. P., J. P. Meehan \& P. M. Stephens. 1967. The use of psychosocial stimuli to induce systolic hypertension in mice. Psychosom. Med. 29: 408-415.

18. Hines, E. A., JR. 1950. Vascular reactivity and hypertensive disease. Collect. Pap. Mayo Clin. Thayo Found. 42: 317-325.

19. Thomas, C. B., J. A. Stanley \& M. A. Kendrick. 1961. Observations on some possible precursors of essential hypertension and coronary artery disease-VII. The subjective reaction to the cold pressor test as expressed in the verbal response. J. Chron. Dis. 14: 355-365.

20. Eich, R. H. \& E. C. JACOBSEN. 1967. Vascular reactivity in medical students followed for 10 years. J. Chron. Dis. 20: 583-592.

21. Armstrong, H. G. \& J. A. Rafferty, 1950. Cold pressor test follow-up study for 7 years on 166 officers. Am. Heart J. 39: 484-490.

22. Harlan, W. R., JR., R. K. Osborne \& A. Graybiel. 1964. Prognostic value of the cold pressor test and the basal blood pressure: Based on an 18 year follow-up study. Am. J. Cardiol. 13: 683-687.

23. Thomas, C. B. 1952. The heritage of hypertension. Am. J. Med. Sci. 224: 367-376.

24. Lund-Johansen, P. 1967. Hemodynamics in early essential hypertension. Acta Med. Scand. Suppl. 482: 1-105.

25. Julius, S. \& J. Conway. 1968. Hemodynamic studies in patients with borderline blood pressure elevation. Circulation 38: 282-288.

26. SANNERSTEDT, R. 1966. Hemodynamic response to exercise in patients with arterial hypertension. Acta Med. Scand. Suppl. 458: 1-83.

27. Levy, A. M., B. S. Tabaxin \& J. S. Hanson. 1967. Hemodynamic responses to graded treadmill exercise in young untreated labile hypertensive patients. Circulation 35: 1063-1072.

28. EsLer, M. D. \& P. J. Nestel. 1973. Sympathetic responsiveness to head-up tilt in essential hypertension. Clin. Sci. 44: 213-226.

29. Frohlich, E. D., R. C. Tarazi, M. Ulrych, et al. 1967. Tilt test for investigating a neural component in hypertension. Circulation 36: 387-393.

30. Nestel, P. J. 1969. Blood pressure and catecholamine excretion after mental stress in labile hypertension. Lancet 1: 692-694.

31. HeNRY, J. P. 1976. Understanding the early pathophysiology of essential hypertension. Geriatrics 31: 59-72.

32. Oberman, A., N. E. Lane, W. R. Harlan, et al. 1967. Trends in systolic blood pressure in the Thousand Aviator Cohort over a 24-year period. Circulation 36: 812-822.

33. ThомAs, C. B. 1969. Developmental patterns in hypertensive cardiovascular disease: Fact or fiction? Bull. N.Y. Acad. Med. 45: 831-850. 
34. Stamler, J., et al. 1976. Relationship of multiple variables to blood pressureFindings from four Chicago epidemiologic studies. In Proceedings of the Second Symposium on the Epidemiology of Hypertension. Symposia Specialists. Miami, N.Y.

35. Levy, R. L., P. D. White, W. D. Stroud, et al. 1945. Transient tachycardia: Prognostic significance alone and in association with transient hypertension. JAMA 129: 585-588.

36. Julius, S., C. N., Ellis, A. V. Pascual, M. Matice, L. Hansson, S. N. Hunyor \& L. N. SANDLER. 1974. Home blood pressure determinations: value in borderline ("labile") hypertension. JAMA 229: 663-666.

37. Thomas, C. B., D. C. Ross \& C. Q. Higinbotham. 1964. Precursors of hypertension and coronary disease among healthy medical students: Discriminant function analysis-II. Using parental history as the criterion. Bull. Johns Hopkins Hosp. 115: 245-264.

38. Harburg, E., S. Julius, N. F. MCGIN, et al. 1964. Personality traits and behavioral patterns associated with systolic blood pressure levels in college males. J. Chron. Dis. 17: 405-414.

39. Kalis, B. L., R. E. Harris, L. F. Bennett, et al. 1961. Personality and life history factors in persons who are potentially hypertensive. J. Nerv. Ment. Dis. 132: $457-468$.

40. TномАs, C. B. 1967. The psychological dimensions of hypertension. In The Epidemiology of Hypertension: Proceedings of an International Symposium. J. Stamler, R. Stamler, \& T. N. Pullman, Eds. : 332-339. Grune \& Stratton. New York.

41. National Health Survey. Vital and Health Statistics. Blood Pressure of persons 18-74 years. United States 1971-72. Series 11, Number 150.

42. Folkow, B., G. Grumby \& O. Thulesius. 1958. Adaptive structural changes of the vascular wall in hypertension and their relationship to control of the peripheral resistance. Acta Physiol. Scand. 44: 255-272.

43. SIVERTSSON, R. 1970. The hemodynamic importance of structural vascular changes in essential hypertension. Acta Physiol. Scand. 79 (Suppl. 343): 3-56.

44. Frohlich, E. D., R. C. Tarazi \& H. P. Dustan. 1971. Clinical-physiological correlation in the development of hypertensive heart disease. Circulation 44: 446-455.

45. McCubbin, J. W., J. H. Green \& I. H. Page. 1956. Baroreceptor function in chronic renal hypertension. Circ. Res. 4: 205-210.

46. Nestel, P. J. \& A. E. Doyle. 1968. The excretion of free noradrenaline and adrenaline by healthy young subjects and by patients with essential hypertension. Aust. Ann. Med. 17: 295-299.

47. Frohlich, E. D. V., J. Kozul, R. C. Tarazi, et al. 1970. Physiological comparison of labile and essential hypertension. Circ. Res. 46 (Suppl. 1): 55-69.

48. Eluis, C. N. \& S. Julius 1973. Role of central blood volume in hyperkinetic borderline hypertension. Br. Heart J. 35: 450-455.

49. Julius, S., O. S. Randall, M. D. Esler, T. Kashima, C. N. Ellis \& J. Bennett. 1975. Altered cardiac responsiveness and regulation in the normal cardiac output type of borderline hypertension. Circ. Res. 36-37 (Suppl. I): I-199-I-207.

50. Safar, M. E., Y. A. Weiss, J. A. Levenson, et al. 1973. Hemodynamic study of 85 patients with borderline hypertension. Am. J. Cardiol. 31: 315-319.

51. Julius, S., A. V. Pascual, R. SanNerstedt, et al. 1971. Relationship between cardiac output and peripheral resistance in borderline hypertension. Circulation 43: 382-390

52. Tarazi, R. C., M. M. Ibrahim, H. P. Dustan, et al. 1974. Cardiac factors in hypertension. Circ. Res. 34-35 (Suppl. I): I-213-I-243.

53. Julius, S., A. V. Pascual, K. Reilly, et al. 1971. Abnormalities of plasma volume in borderline hypertension. Arch. Intern. Med. 127: 116-119.

54. Esler, M. D., S. Julius, O. S. RANDall, et al. 1975. Relation of renin status to 
neurogenic vascular resistance in borderline hypertension. Am. J. Cardiol. 36: 708-715.

55. Suck, A. F., Mendlowitz, R. L. Wolf, et al. 1971. Identification of essential hypertension in patients with labile blood pressure. Chest 59: 402-406.

56. Frohlich, E. D., R. C. Tarazi \& H. P. Dustan. 1969. Hyperdynamic betaadrenergic circulatory state: increased beta-receptor responsiveness. Arch. Intern. Med. 123: 1-7.

57. Kuchel, O., J. L. Cuche, P. Hamet, et al. 1972. The relationship between adrenergic nervous system and renin in labile hyperkinetic hypertension. In Hypertension-1972. J. Genest \& E. Koiw, Eds. : 118-125. Springer-Verlag. New York.

58. Mark, A. L., W. J. LAwton, F. M. Abboud, et al. 1975. Effects of high and low sodium intake on arterial pressure and forearm vascular resistance in borderline hypertension. Circ. Res. 36-37 (Suppl. I): I-194-I-198.

59. JULIUS, S. \& M. EsLeR. 1975. Autonomic nervous cardiovascular regulation in borderline hypertension. Am. J. Cardiol. 36: 685-696.

60. Julius, S., A. V. Pascual \& R. London. 1971. Role of parasympathetic inhibition in the hyperkinetic type of borderline hypertension. Circulation 44: 413418.

61. Esler, M. E., S. Julius, A. ZWeifler, et al. 1977. Mild high-renin essential hypertension: A neurogenic human hypertension. N. Engl. J. Med. 296: 406407.

62. Esler, M., S. Julius \& O. Randall. 1976. Relationship of volume factors, renin and neurogenic vascular resistance in borderline hypertension. In The Arterial Hypertensive Disease-A Symposium. G. Rorive \& H. Van Cauwenberge, Eds. : 231-248. P. Masson. Paris.

63. Esler, M., A. Zweifler, O. Randall, S. Julius, J. Bennett \& P. Rydelek. 1976. Suppression of sympathetic nervous function in low-renin essential hypertension. Lancet 2: 115-118.

64. Eich, R. H., R. J. Peters, R. P. Cuddy, et al. 1962. The hemodynamics in labile hypertension. Am. Heart J. 63: 188-195.

65. Finkielman, S., M. Worcel \& A. Agrest. 1965. Hemodynamic patterns in essential hypertension. Circulation 31: 358-368.

66. Bello, C. T., R. W. Sevy, C. Harakal, et al. 1967. Relationship between clinical severity of disease and hemodynamic patterns in essential hypertension. Am. J. Med. Sci. 253: 194-208.

67. Widimsky, J., M. H. Fejfaroví \& Z. Fejar. 1957. Changes of cardiac output in hypertensive disease. Cardiologia 31: 381-389.

68. Eich, R. H., R. P. Cuddy, H. Smulyan, et al. 1966. Hemodynamics in labile hypertension: A follow-up study. Circulation 34: 299-307.

69. Zinner, S. H., H. S. Margolius, B. Rosner, et al. 1976. Familial aggregation of urinary kallikrein concentration in childhood: relationship to blood pressure, race, and urinary electrolytes. Am. J. Epidemiol. 104: 124-132.

70. Guyton, A. C. \& T. G. Coleman. 1969. Quantitative analysis of the pathophysiology of hypertension. Circ. Res. 24-25 (Suppl. I): I-1-I-19. 